\title{
LEITURA, INTERPRETAÇÃO E TRANSCRIAÇÃO: CONCEPÇÕES DO ATO TRADUTÓRIO ENTRE ESTUDIOSOS DA FILOSOFIA ALEMÃ
}

\author{
Maria Claudia Bontempi PIZZI* \\ Cibele Cecilio de Faria ROZENFELD**
}

- Resumo: $\mathrm{O}$ interesse na aprendizagem de alemão é frequentemente desencadeado pelo desejo e pela necessidade de leitura de textos alemáes em sua língua de partida, fato comumente observável entre alunos oriundos do campo da filosofia. Este trabalho tem o intuito de apresentar um curso de alemão elaborado na modalidade a distância para estudiosos do campo da filosofia - que buscavam aprimoramento linguístico para melhor compreenderem textos em língua de partida da área - e de lançar luzes sobre diferentes concepçóes de tradução. Para tanto, descreveremos o curso realizado e analisaremos as discussóes de quatro fóruns online, buscando identificar as noçôes de tradução imbuídas entre os participantes do curso. Os resultados apontam, de um lado, para a validade de cursos a distância para o trabalho com alunos de alemão com demandas específicas, por exemplo, que buscam a compreensão e tradução de textos filosóficos; por outro lado, foi possível reconhecer diferentes concepçóes de tradução. Buscamos com este trabalho contribuir para o campo dos estudos tradutórios, ao mesmo tempo em que evidenciamos um caminho interessante a ser percorrido no campo do ensino e aprendizagem de alemão como língua estrangeria.

- Palavras-chave: Ensino e aprendizagem de alemão como língua estrangeira. Alemão instrumental para leitores de filosofia. Ato tradutório. Ensino de alemão à distância.

\section{Introdução}

Antes de expormos este trabalho, é importante destacar que tomamos o ato tradutório em seu sentido mais amplo: aquele que envolve adaptar um texto, em todas as suas facetas, de uma língua para outra, de uma realidade para outra, ou de um gênero para outro e assim por diante.

\footnotetext{
* IFSP - Instituto Federal de Educação, Ciência e Tecnologia de São Paulo. Piracicaba - SP - Brasil. 13414-155 - mclaudiapizzi@yahoo.com.br.

** UNESP - Universidade Estadual Paulista - Departamento de Letras Modernas. Araraquara - SP Brasil.1480-901 - cibeleroz@fclar.unesp.br.
} 
A tradução também pode ser vista como leitura e interpretação, o que faz de todos nós, leitores, também tradutores. Ao lermos alguns textos, podemos pensar em traduçóes para certos termos de acordo com a leitura que fazemos de determinado autor, além de sermos influenciados por nosso conhecimento de mundo, nossa formação acadêmica e nossa vida social, por exemplo.

$\mathrm{Na}$ área de estudos tradutológicos, há também diferentes formas de se pensar o ato tradutório, cada uma delas dando mais ou menos liberdade ao tradutor, que pode ser visto tanto como um segundo autor quanto como um traidor. A partir, por exemplo, do ponto de vista da "desconstruçáa", termo criado por Derrida (1998), pode-se entender que o ato tradutório deve tomar o texto como textura de significaçóes que não são hierarquizáveis e irredutíveis a sentidos únicos e que, portanto, dependem da leitura de seu tradutor e das escolhas que ele faz. Há fatalmente uma alteração do sentido, pois não existe tradução "pura", que não esteja "assujeitada", que não se afete a partir das escolhas efetuadas pelo tradutor. Traduzir seria, portanto, uma leitura do texto de partida que transforma a lógica do texto, construindo outra lógica. Assim, entendemos a tradução como uma conciliação instável entre dois produtos diferentes, às vezes conflitantes, o que torna a intervenção do tradutor/leitor decisiva e faz do seu trabalho uma transcriação, termo definido por Haroldo de Campos (1992, p.35):

Então, para nós, tradução de textos criativos será sempre recriação, ou criação paralela, autônoma porém recíproca. [...]. Numa tradução dessa natureza, não se traduz apenas o significado, traduz-se o próprio signo, ou seja, sua fisicalidade, sua materialidade mesma (propriedades sonoras, de imagética visual, enfim tudo aquilo que forma, segundo Charles Morris, a iconicidade do signo estético, entendido por signo icônico aquele "que é de certa forma similar àquilo que ele denota"). O significado, o parâmetro semântico, será apenas táo-somente a baliza demarcatória do lugar da empresa recriadora. Está-se pois no avesso da chamada tradução literal.

Por sua vez, os teóricos que pregam o logocentrismo ${ }^{1}$, posição contrária à de Derrida, buscam definir uma tipologia geral ou um modelo, um método a ser seguido pelo tradutor no momento do ato tradutório na esperança de tornar a traduçáo algo mais objetivo e, portanto, menos artístico, visto que o tradutor não teria espaço para exercer sua criatividade. A busca por uma verdade única e absoluta não abre possibilidades diversas para a tradução de um mesmo texto, e o texto de partida é visto como o verdadeiro, o texto que deve ser conservado.

A tradução pode, ainda, ser vista como infidelidade, conforme Sá (1996, p.76):

1 O logocentrismo remete a logos (a razão, a palavra de Deus, a fala, o discurso), em especial a significação relacionada à busca pela verdade absoluta. 
Ao retomar a famosa analogia entre traduttore/traditore, pode-se numa repetição indiferencial e numa (pseudo)tipologia tripartite, comparar a tradução à infidelidade e traição: ao original, à língua-mãe do tradutor e ao desenvolvimento de uma literatura nacional.

Portanto, tendo em vista os pressupostos teóricos expostos, este trabalho tem como objetivo analisar a que concepçóes de tradução os participantes de um curso de leitura de textos filosóficos mais parecem se aproximar. O referido curso, intitulado Deuschlesekurs: deutsche Philosophen (doravante DLdP), foi oferecido na modalidade a distância, prioritariamente a estudiosos da filosofia alemã, e idealizado/desenvolvido como extensão universitária por pesquisadores de uma universidade do interior de São Paulo.

Acreditamos que tal discussáo seja relevante para áreas como filosofia, tradução, literatura, linguística e ensino de língua alemã, pois, a partir das reflexôes instigadas por tal curso, foi possível observar conceitos de tradução/papel do tradutor intrínsecos em cada indivíduo, mesmo naqueles que não tinham conhecimento direto de teóricos da área. Também foi possível notar, a partir das justificativas em fórum para determinadas escolhas tradutórias, como os leitores proficientes em alemão constroem suas concepçôes e fazem suas leituras/traduçôes de termos filosóficos a partir do seu conhecimento de língua estrangeira e materna, bem como de sua formaçáo como sujeito social, político e acadêmico. Vale ressaltar ainda que, durante as atividades, verificouse outra tendência relevante: foram oferecidas oportunidades de tradução coletiva e colaborativa nos fóruns, o que reflete a realidade interativa dos cursos online e, ao mesmo tempo, exemplifica uma prática que vem se consolidando e democratizando a partir da internet: muitas vezes interessados em literatura, filmes, música e seriados formam grupos para traduzir/legendar textos ou episódios inéditos em português antes mesmo que a versão oficial seja lançada.

Apresentaremos, a seguir, as discussóes teóricas que fundamentaram o trabalho, descreveremos, então, a metodologia utilizada, o contexto e os participantes; apresentaremos, entâo, alguns resultados e a discussão dos dados e, finalmente, nas consideraçóes finais, refletiremos sobre o processo tradutório fundamentado no contexto observado e em teorias sobre a tradução.

\section{Discussão teórica: tradução como leitura, interpretação e identidade}

De acordo com Paz (1990), quando um povo se vê diante de um modo diferente de comunicação oral pela primeira vez, sua crença em uma linguagem universal é substituída por uma noção de pluralidade de línguas. O autor advoga que, no passado, a tradução seguia a seguinte reflexão: se não havia uma língua universal, havia uma sociedade formada pelas diversas línguas na qual todos, vencidas algumas barreiras, 
poderiam se entender, porque mesmo fazendo uso de léxicos diferentes, os homens sempre diziam as mesmas coisas. "A universalidade do espírito era a resposta para a confusão babélica: há muitas línguas, mas o sentido é único" (PAZ, 1990, p.10, tradução nossa²).

Já na Idade Moderna, ainda de acordo com Paz (1990), com o desenvolvimento das navegaçóes e o descobrimento de "novos mundos", houve uma reviravolta no rumo da tradução. A segurança religiosa de uma identidade universal é substituída pela curiosidade intelectual em conhecer mais e mais diferenças. Refletindo essas mudanças, a tradução não é mais uma operação que mostra uma única identidade para o homem, mas suas singularidades. O mundo deixa de ser indivisível: "pluralidade de línguas e sociedades: cada língua é uma visão de mundo" (PAZ, 1990, p.12, tradução nossa 33). Até mesmo dentro de cada língua destacam-se diferenças e divisóes, como períodos históricos, classes sociais e geraçôes. Mas, o que deveria ter desanimado os tradutores, teve um efeito inverso, o que Paz (1990, p.13, tradução nossa $\left.{ }^{4}\right)$ explica na transcrição abaixo:

A razão deste paradoxo é a seguinte: por um lado a tradução suprime as diferenças entre uma língua e outra; por outro, as revela mais plenamente: graças à tradução nos inteiramos de que nossos vizinhos falam e pensam de um modo distinto do nosso.

Rodrigues (2000) também argumenta que a tradição sempre considerou que o acesso à origem seria livre e pleno. Os próprios termos usados na tradução pressupóem, aliás, a existência de uma origem, de uma fonte que encerraria o sentido primeiro, intencionado pelo autor (texto de partida, texto-fonte). Porém, remetendo mais uma vez a Derrida (1998), pode-se concluir que a relação do leitor com o texto náo pode ser de regresso ao original, visto que este pertence a um momento único que nem mesmo o autor recupera. Shreve (1997, p.23, tradução nossa) $)^{5}$ compartilha tal noção quando afirma:

\footnotetext{
2 "La universalidad del espiritu era la respuesta a la confusión babélica: hay muchas lenguas, pero el sentido és uno" (PAZ, 1990, p.10).

3 No texto de partida: "[...] pluralidad de lenguas y sociedades: cada lengua es una visión del mundo" (PAZ, 1990, p.12).

$4 \quad$ No texto de partida: "La razón de esta paradoja es la siguiente: por una parte la traducción suprime las diferencias entre una lengua y otra; por la otra, las revela más plenamente: gracias a la traducción nos enteramos de que nuestros vecinos hablan y piensan de un modo distinto al nuestro" (PAZ, 1990, p.13).

5 No texto de partida: "It is not my purpose here to delineate the possible forms of translation but to argue that there is no one form of translation, and that even in the same individual, translation is carried out in different ways under different conditions. This fact has been long recognized in translation studies" (SHREVE, 1997, p.123).
} 
O meu objetivo aqui não é delinear as possíveis formas de tradução, mas argumentar que não há apenas uma maneira de se traduzir, e que o mesmo indivíduo pode desenvolver a tradução de maneiras diferentes sob circunstâncias diversas. Esse é um fato reconhecido há muito tempo nos estudos tradutórios.

Acreditar que o texto de partida é uma fonte clara de significados é ignorar o fato de que ele já é o "signo de um signo" e não uma representação perfeita e direta do pensamento. $\mathrm{O}$ tradutor, portanto, não lida com uma fonte permanente ou uma origem fixa, mas constrói uma interpretação que também vai gerar outras interpretaçôes:

O texto traduzido é "outro" texto, que mantém outro tipo de relaçôes entre os elementos, exatamente porque as coerçóes impostas pelas línguas levam a diferentes possibilidades de contextualizaçóes, de remissóes, de encadeamentos, de atribuição de valores entre os elementos (RODRIGUES, 2000, p.205).

Ottoni (1997) afirma que a tradução pratica a diferença entre significado e significante e conclui, a partir de tal afirmação, que assim como a relação acima nunca é pura, a tradução também não poderia ser e, portanto, é vista como uma transformação. Traduzir, então, é se movimentar entre uma língua materna e uma estrangeira graças à produção e transformação de significados:

A ciência linguística dificulta a compreensáo do ato de traduzir partindo da postura do tradutor como transportador de significados estáveis de um sistema - de uma língua - para outro, aquele que vai transportar significados entre dois sistemas fechados e diferentes entre si. [...] Para transformar e produzir outros significados numa outra língua, é fundamental partir da multiplicidade do significado. Só assim o tradutor participa de um fenômeno mais amplo que envolve a linguagem e não só a língua (OTTONI, 1997, p.133, grifo do autor).

A atividade do tradutor é, então, parecida com a do leitor e a do crítico: cada leitura é uma tradução - "nenhuma leitura é tão atenta e tão cuidadosa quanto aquela que compóe a mais simples das traduçóes bem realizadas" (ARROJO, 1993, p.52). Para Arrojo (1993), "traduzir" pode significar "interpretar", e ao tradutor cabe um papel de intermediário, que resgata significados e os transporta para o outro lado, construindo uma ponte entre os dois planos, pois os estilos são coletivos, universais e passam de uma língua para outra.

A tradução, se encarada como um processo de reprodução de sentidos equivalentes aos do texto de partida, leva em conta que é possível recuperar dados do texto ou do escritor a partir da leitura e que é igualmente possível a sua passagem para outra língua. Porém, ainda segundo Arrojo (1992), o que causa grande problema para a maioria das teorias de tradução é a já citada ligação inevitável que qualquer tradução mantém com 
uma interpretação, pois toda tradução, por mais simples e breve que seja, é produto de uma perspectiva, de um sujeito interpretante, afastando qualquer possibilidade de sistematização, normalização. A sistematização da interpretação e da compreensão não poderia ser possível, mesmo porque tal ato negaria tudo o que constitui e caracteriza o ser humano, como a subjetividade, o inconsciente, e assim por diante.

Há, porém, os estudiosos que buscam uma tipologia para a área. O logocentrismo parte de três pressupostos que indicam a possibilidade de uma distinção clara, bem delineada entre sujeito e objeto. São eles:

1) a noção de uma tradução "literal", próxima do "original", que não apresentaria nenhuma interferência do tradutor, em oposiçáo à noção de uma tradução "literária", que revelaria a interferência da interpretaçáo e do julgamento do tradutor;

2) a concepção de um texto "original", estável e imutável, depositário das intençôes e dos significados (conscientes, apenas) de um autor, recuperáveis através da leitura, considerada, por sua vez, como um processo neutro, que pode e deve eliminar as interferências do leitor e de seu contexto sócio-cultural e histórico;

3) a noção de significado como um objeto distinto do estilo em que aparece "acondicionado" (ARROJO, 1992, p.74).

Já a desconstrução, uma visão mais radical do ato tradutório que abandona por completo a busca da equivalência, do sentido único, significa desconstruir e reconstruir sentidos, ou seja, um deslocamento. Isso quer dizer que os sentidos não são sempre os mesmos, que há uma flutuação, um efeito de sentido.

Essa concepção conduz à necessidade de negar a ideia de significado inscrito, fixo e imutável, porque tanto a leitura quanto a escrita se constroem em um presente circunscrito pelo tempo e espaço e em cada nova escritura.

Bayard ainda escreve que o crítico (considerado aqui também como leitor e tradutor) deve ser avaliado pelo tratamento que dá à ideia principal e não por sua fidelidade: "A crítica é a voz de uma alma, e essa alma é seu objeto profundo, não as obras literárias transitórias que servem de suporte à busca" (BAYARD, 2007, p.197). Dessa forma, o tradutor pode ser reconhecido como um segundo-autor, e nấo como um "traidor", alguém que corrompe a obra de partida. Deve ocorrer, segundo Bayard (2007, p.203), uma "evolução psicológica":

[...] implica antes de mais nada conseguirmos nos livrar de toda uma série de interdiçôes, o mais das vezes inconscientes, que pesam sobre nossas representaçóes dos livros e que nos conduzem a pensá-los, desde os anos escolares, como objetos intangíveis, e portanto a nos fazer sentir culpados sempre que os fazemos sofrer transformaçóes. 
Grigoletto (1992) reitera a proposta desconstrutivista ao escrever que o sentido se constrói por meio da interaçáo entre o leitor, o texto e o autor. O significado, em toda a sua instabilidade, é composto no ato da leitura, a partir de uma base explícita e literal já dada, sem a qual não seria possível a existência de semelhanças de interpretação. Diante da polissemia, a compreensão da linguagem entre sujeitos é possível porque a interação ocorre a partir de um discurso determinado social e historicamente, além de institucionalizado. Não há uma base imutável no texto, mas cada discurso está inserido em uma determinada formação ideológica que regula a produção de significados. "A constituiçẫo de sentidos é, pois, social" (GRIGOLETTO, 1992, p.95). O projeto de desconstruçáo de Derrida, portanto, valoriza a posição do sujeito/leitor/tradutor ao reconhecer sua interferência em qualquer texto. Entretanto, para tornar possível a própria comunicação/expressão humana através da linguagem, a ilusão do significado atingido, da construção do signo tem de ocorrer.

No Brasil, tais noçôes estão presentes também na tipologia de Campos (1992), que defende que não se traduz o que é linguagem em um texto, mas o que não o é, advogando uma atividade de tradução que é análoga à criação e, portanto, poética (TÁPIA; NÓBREGA, 2013, p.XVIII):

Em vez de buscar reconstruir um mundo passado, a visão haroldiana decide pela reinvenção de uma tradição, inserida em um novo contexto: o texto, portanto, transforma-se na "viagem", e seu ponto de chegada acolhe-o de modo a participar de sua reestruturação, para a qual o presente, a releitura e a comunicação em novo espaço e em novo tempo são determinantes.

Segundo Alves-Bezerra, Campos define o tradutor como alguém que tem a chance de recriar o original a partir das potencialidades da língua alvo, que deve colocar-se como poeta e traduzir poesia com outra poesia, criando no tradutor um sentimento de liberdade e, ao mesmo tempo, de responsabilidade criativa "pois a escolha nunca será aleatória e deverá ser sustentável, pois há que haver uma relação de reciprocidade entre original e tradução" (ALVES-BEZERRA, 2009, p.71). Para Campos, entâo, se "o poeta é um fingidor", de acordo com o poema de Fernando Pessoa (vide epígrafe), o tradutor é um "transfingidor" (CAMPOS, 2013a, 2013b).

A partir da experiência de quem chegou a traduzir poemas de Baudelaire, o filósofo Walter Benjamin (2008) também discorre sobre a tarefa do tradutor em um dos textos que figuram como cânones da área e que fez parte das leituras e discussóes do curso que será aqui apresentado.

Da mesma forma que alguns autores pregam a polissemia lexical em lugar do significado fixo, segundo o autor, ao elaborar uma traduçáo, o tradutor náo deve tentar identificar quem/como seriam os receptores do texto original, da mesma forma que não deve buscar apoio em ponderaçóes sobre quais serão os leitores do texto traduzido, pois essa reflexão não contribui para a tarefa tradutória, já que "o próprio conceito 
de um leitor 'ideal' é nefasto em quaisquer indagações de caráter estético, pois devem pressupor unicamente a existência e a natureza do homem em geral" (BENJAMIN, 2008, p.66).

Segundo ele, longe de apenas transcrever ou transmitir, cabe ao tradutor um trabalho criativo, pois "aquilo que está numa obra literária, para além do que é comunicado [...] não será isto aquilo que se reconhece em geral como o inaferrável, o misterioso, o 'poético'? Aquilo que o tradutor só pode restituir ao tornar-se, ele mesmo, um poeta?” (BENJAMIN, 2008, p.66). Dessa forma, a tradução também contribui para a sobrevivência do original, conferindo-lhe desdobramentos geográficos e temporais.

A tarefa do tradutor, enfim, "consiste em encontrar na língua para a qual se traduz a intençáo, a partir da qual o eco do original é nela despertado. [...] A intenção do escritor é ingênua, primeira, intuitiva; a do tradutor derivada, última, ideativa" (BENJAMIN, 2008, p.75).

Assim, ao invés de vista com desconfiança, a tradução pode ser considerada um ponto de partida para o aprofundamento das reflexóes acerca de questóes da linguagem, pois o tradutor não precisa descartar o humano, o contextual e o histórico durante a produção de seu trabalho.

Derrida (1998, p.24) deixa claro que é difícil definir um significado para desconstrução porque:

[...] a palavra "desconstrução", como qualquer outra, não extrai seu valor senão da sua inscrição em uma cadeia de substituiçôes possíveis, naquilo que se chama, táo tranquilamente, de um "contexto". [...] Efetivamente, teria sido preciso citar frases e encadeamentos de frases que, por sua vez, determinam, em alguns de meus textos, esses nomes. O que a desconstrução não é? É tudo! O que é a desconstrução? É nada!

Portanto, "desconstrução" é leitura, é interpretação, é tradução. Em cada nova leitura, o indivíduo "desconstrói" o texto com o qual se depara, formulando uma interpretação com base em sua própria experiência cultural e social, para que possa, a partir de sua visão de mundo aplicada nos escritos de um autor qualquer, "construir" um novo texto.

Ao imprimir no texto a sua forma de expressão, o tradutor deixa, portanto, marcas de seu ethos, ou seja, de sua voz, de seu tom. De acordo com Martins (2007, p.28), o ethos é anterior ao discurso, visto que "significa o aspecto moral que o locutor, com diferentes intençóes, deixa transparecer em seu discurso". Ainda segundo a mesma autora, o ethos pode apresentar um sentido moral relacionado à transparência do discurso, à sinceridade inerente ao ser humano (como postulava Aristóteles) e um sentido de adequação ao tipo social (idade, classe, etc.) tanto do "orador" como do "auditório" (em termos aristotélicos), fazendo com que o público identifique-se com o locutor. 
Seguindo o mesmo raciocínio, podemos comentar o conceito de Benveniste (2005) sobre a subjetividade da linguagem, que está presente na capacidade do locutor para se propor como sujeito. Falar uma língua não engloba apenas o conhecimento de técnicas, então, é necessário aprofundar-se no sentido heurístico, na pessoalidade. $\mathrm{O}$ "eu" se apresenta como sujeito em seu discurso e os pronomes pessoais, que existem na língua como signos vazios, só adquirem sentido dentro de um discurso. Incorporamos maneiras de ser a esse "eu" (modelos como pai, mãe, professor nos influenciam), pois apesar de cada um ter a sua forma de falar, ela não é completamente original.

Coracini (2009) promove, mais especificamente, reflexóes sobre a figura identitária do tradutor a partir da análise de artigos publicados em periódicos dedicados especialmente à tradução, prefácios de obras traduzidas e coletâneas de textos sobre tradução. Segundo ela, os teóricos da área e os próprios tradutores, por exemplo, podem seguir duas linhas diferentes de pensamento. Alguns consideram que "o bom tradutor ou o tradutor ideal é aquele que desaparece para dar lugar ao autor; é aquele que consegue ser tão fiel ao autor e, portanto, à obra que se torna transparente apenas um instrumento que se retira tâo logo a obra se completa" (CORACINI, 2009, p.171). O tradutor é um sujeito racional, uno e completo, portanto, e possui algumas características fundamentais para realizar tal atividade: proficiência linguística, proficiência temática, saber interpretar, competência estratégica, ser capaz de produzir no leitor o desejo de ler, competência temática e lexical, competência pragmática, etc. Para outros pesquisadores, "imprime-se ao tradutor a tarefa de autor, porque, ao traduzir, modifica, sempre e inevitavelmente, o texto que interpreta, produzindo novos significados" (CORACINI, 2009, p.173). O tradutor passa a sujeito inconsciente, heterogêneo e fragmentado, que sofre influências do contexto histórico em que está inserido.

Há atualmente, então, de acordo com Coracini (2009, p.179), um quadro de ecletismo teórico:

[...] uma região de conflitos entre o desejo de fidelidade e de reverência ao autor do texto-base e o desejo de ser o lugar da origem, de ser completo, que se traduz na ânsia de criatividade e de autoria: ao mesmo tempo em que defende a tradução como criação, o tradutor ou o autor do texto traduzido afirma se ater a cada palavra na preocupação com o sentido do texto.

Então, traduzir é um ato individual que, obviamente, sofre influências de seu tradutor e do meio em que o mesmo formou sua maneira de ver o mundo e de interpretar o pensamento de outras pessoas. Por tal essência, a teoria da tradução nasce a cada nova tradução e em cada novo tradutor.

Tendo discorrido sobre as teorias acerca do ato tradutório, descreveremos no próximo item o contexto analisado, para, então, apresentar a discussão dos resultados das análises. 


\section{Percurso metodológico e o contexto tradutório}

As reflexões e análises apresentadas neste trabalho foram obtidas a partir de um curso intitulado Deutschlesekurs: deutsche Philosophen, oferecido a alunos interessados em discutir textos em alemão (de literatura primária e secundária) de/sobre filósofos alemães, ao longo de 7 meses $^{6}$. A idealização do curso decorreu de dois fatores principais: 1) do fato de que muitos interessados na aprendizagem de alemão são da área da filosofia e afins e têm como objetivo primeiro a leitura de pensadores alemães em sua língua de partida e 2) das oportunidades geradas pelos ambientes virtuais para a elaboração de cursos a distância, podendo assim, atender a interessados de diferentes cidades.

Assim, criou-se o Deutschlesekurs: deutsche Philosophen, que foi oferecido como curso de extensão a distância, na plataforma Moodle, de uma universidade no interior de São Paulo, e que teve como objetivos: promover a possibilidade de aprofundamento de conhecimentos linguísticos adquiridos previamente pelos participantes (destaca-se que foi exigido o nível B1 como requisito para inscrição no curso), discutir o conceito de leitura e estratégias de leitura e estimular a discussáo do pensamento de alguns filósofos alemães e seus conceitos.

A fim de oportunizar a participação de profissionais e estudantes de outros campos de conhecimento, e não somente da filosofia, as inscriçôes foram abertas também a pessoas vinculadas às áreas das Ciências Sociais, Direito e Letras, que tivessem interesse em estudos filosóficos.

O grupo de participantes constituiu-se, assim, de 14 pessoas, sendo:

- 1 professora organizadora do curso

- 1 coordenadora geral do programa de extensão

- 1 tutora, doutoranda (trabalho com foco em estudos tradutórios).

Dentre os 11 demais participantes encontravam-se:

- 1 estudante de Direito

- 1 mestranda em Letras (com graduação em alemáo)

- 1 cientista social

- 8 estudantes da área da Filosofia (graduação e pós-graduação)

${ }_{6}$ O DLdP foi desenvolvimento durante uma pesquisa de pós-doutorado e constituído predominantemente ao longo de um estágio de pós-doutorado (PNPD-Capes) de uma das autoras na Universidade Ludwig-Maximiliam de Munique (LMU), sob supervisão do Prof. Dr. Jörg Roche. 
O programa do curso foi abordado em sete módulos distintos e a língua de comunicação nos fóruns foi o Português, uma vez que o foco da proposta estava na leitura de textos e não na produção escrita.

Os módulos 1, 2 e 3 foram dedicados, respectivamente à apresentaçáo dos participantes, à interação entre eles, à discussão sobre estratégias de leitura e, no módulo 3 , à discussão sobre a noção de tradução e à exploração do conhecimento prévio acerca de conceitos centrais de alguns filósofos alemães. Buscou-se, dessa forma, explorar e/ou repensar o sentido de leitura e de tradução previamente à exposiçáo dos participantes aos textos e à realizaçáo das atividades. Os módulos 4 a 7 trataram especificamente de um pensador, conforme pode ser verificado na Tabela 1 .

Durante a constituição dos módulos e das atividades, deparamo-nos com a questáo acerca da natureza dos textos a serem disponibilizados: seria mais pertinente priorizar textos originais dos pensadores ou sobre seus estudos filosóficos, ou seja, textos sobre os estudos filosóficos escritos por outros autores? Considerou-se importante apresentar nas primeiras atividades dos módulos específicos (de 4 a 7), textos de literatura secundária, ou seja, de outros autores que se debateram com os estudos dos filósofos. Porém, ao final de cada um deles, foi inserido ao menos um texto de partida, a fim de promover o contato dos participantes com textos autênticos e a discussão sobre os sentidos.

Apresentamos na Tabela 1 o nome de cada módulo, os objetivos e as atividades propostas. 
Tabela 1 - O Deutschlesekurs: Deutsche Philosophen: módulos, objetivos e atividades

\begin{tabular}{|c|c|c|c|}
\hline & $\begin{array}{l}\text { TEMA DO } \\
\text { MÓDULO }\end{array}$ & OBJETIVOS & $\begin{array}{l}\text { NÚMERO DE ATIVIDADES NO } \\
\text { MÓDULO/TIPO DE FERRAMENTA } \\
\text { UTILIZADA/TEMA OU OBJETIVO }\end{array}$ \\
\hline $\mathbf{M I}^{7}$ & & & $\begin{array}{l}\text { 1. Mensagem de recepção (Begrüßung); } \\
\text { 2. Link para Dicionário online (alemão-alemão); } \\
\text { 3. Link para Programa do curso; } \\
\text { 4. Fórum para postagem de dúvidas }\end{array}$ \\
\hline 1 & $\begin{array}{l}\text { Wir lernen } \\
\text { uns erstmal } \\
\text { etwas kennen }\end{array}$ & $\begin{array}{l}\text { Módulo destinado } \\
\text { às apresentaçóes } \\
\text { dos participantes, } \\
\text { à interaçáo entre } \\
\text { eles e a introduzir o } \\
\text { tema do curso }\end{array}$ & $\begin{array}{l}\text { 1. Fórum "Este/a sou eu" } \\
\text { 2. Vídeo: Gespräch mit einem Philosophen"- } \\
\text { Documentário sobre o filósofo Ernst Bloch } \\
\text { 3. Fórum para discussão de questóes do filme }\end{array}$ \\
\hline 2 & $\begin{array}{l}\text { Auf Deutsch } \\
\text { lesen und } \\
\text { verstehen: } \\
\text { Lesestrategien }\end{array}$ & $\begin{array}{l}\text { Apresentar e refletir } \\
\text { sobre o processo } \\
\text { e as estratégias de } \\
\text { leitura }\end{array}$ & $\begin{array}{l}\text { 1. Link para apresentação Powerpoint sobre a natureza } \\
\text { da leitura e o papel do leitor } \\
\text { 2. Link para apresentação Powerpoint sobre o tema } \\
\text { Estratégias de leitura } \\
\text { 3. Fórum: Discussão sobre as apresentaçóes anteriores } \\
\text { 4. Link para um texto em alemáo para o primeiro } \\
\text { reconhecimento de estratégias. } \\
\text { 5. Fórum: discussão sobre as estratégias utilizadas } \\
\text { durante a leitura do texto anterior }\end{array}$ \\
\hline 3 & $\begin{array}{l}\text { Einführung in } \\
\text { die Deutsche } \\
\text { Philosophie }\end{array}$ & $\begin{array}{l}\text { Discutir sentido de } \\
\text { traduçáo e fazer um } \\
\text { brainstorming dos } \\
\text { conceitos centrais } \\
\text { dos estudiosos } \\
\text { abordados no curso }\end{array}$ & $\begin{array}{l}\text { 1. Wiki: construção coletiva dos conceitos centrais } \\
\text { de cada filósofo abordado no curso (baseada em } \\
\text { conhecimento prévio); } \\
\text { 2. Quiz: foram apresentadas duas definiçóes. A partir } \\
\text { da leitura destas, os participantes deveriam inferir os } \\
\text { conceitos definidos; } \\
\text { 3. Fórum: "O que é traduçáo?" } \\
\text { membros do grupo sobre o tema. } \\
\text { 4. Link para o texto de Walter Benjamim "A tarefa } \\
\text { do tradutor" (foram disponibilizadas as versóes em } \\
\text { alemão e em português) } \\
\text { 5. Fórum: Discussão sobre o texto de Walter Benjamim }\end{array}$ \\
\hline
\end{tabular}

\footnotetext{
7 MI=Módulo Introdutório: este módulo esteve aberto ao longo de todo o curso. Os demais foram abertos (e fechados após a finalização das atividades) paulatinamente, de acordo com o calendário do curso.
}

8 As atividades destacadas em negrito referem-se aos fóruns que constituíram o corpus de análise. 


\begin{tabular}{|c|c|c|c|}
\hline & $\begin{array}{l}\text { TEMA DO } \\
\text { MÓDULO }\end{array}$ & OBJETIVOS & $\begin{array}{l}\text { NÚMERO DE ATIVIDADES NO } \\
\text { MÓDULO/TIPO DE FERRAMENTA } \\
\text { UTILIZADA/TEMA OU OBJETIVO }\end{array}$ \\
\hline 4 & $\begin{array}{l}\text { Georg W.F. } \\
\text { Hegel } \\
(1770-1831)\end{array}$ & $\begin{array}{l}\text { Ler, compreender } \\
\text { e discutir ideias } \\
\text { centrais e textos de/ } \\
\text { sobre os estudos } \\
\text { de Hegel (Textos } \\
1 \text { e } 2 \text { : literatura } \\
\text { secundária, texto } \\
\text { 3: original) }\end{array}$ & $\begin{array}{l}\text { TEXTO 1: "HEGELS PHILOSOPHISCHE } \\
\text { ANFÄNGE" } \\
\text { 1. Brainstorming sobre conhecimento prévio } \\
\text { 2. Orientaçóes para a leitura } \\
\text { 3. Apresentaçáo do texto } \\
\text { 4. Discussão. } \\
\text { TEXTO 2: "ANFÄNGE DER DIALEKTIK" } \\
\text { 5. Questóes de compreensáo para entrega em atividade } \\
\text { individual } \\
\text { 6. Wiki: Construção colaborativa das ideias centrais } \\
\text { do texto } \\
\text { TEXTO 3: "DIE ABSOLUTE IDEE" } \\
\text { 7. Apresentação de estratégias-reflexôes a serem feitas } \\
\text { previamente à leitura/questôes sobre um excerto do } \\
\text { texto } \\
\text { 8. Fórum: discussão das ideias do texto/das respostas } \\
\text { às questóes } \\
\text { 9. Atividade individual: trabalho com o léxico } \\
\text { (substantivos) e sintaxe (os casos Nom., Akk., Dat.) }\end{array}$ \\
\hline 5 & $\begin{array}{l}\text { Immanuel } \\
\text { Kant } \\
(1724-1804)\end{array}$ & $\begin{array}{l}\text { Ler, compreender } \\
\text { e discutir ideias } \\
\text { centrais e textos de/ } \\
\text { sobre os estudos } \\
\text { de Kant (Textos } \\
1,2 \text { e } 3: \text { literatura } \\
\text { secundária) }\end{array}$ & $\begin{array}{l}\text { TEXTO 1: INHALTSÜBERSICHT: BUCH "KANT } \\
\text { HANDBUCH: LEBEN UND WERK" } \\
\text { 1. Link: apresentação do sumário do manual de Kant } \\
\text { 2. Fórum para discussão de questóes sobre o sumário } \\
\text { TEXTO 2: "KANT IN DER ZEIT DER } \\
\text { AUFKLÄRUNG" } \\
\text { 3. Recurso: Orientaçóes prévias à leitura do texto. } \\
\text { Apresentação do texto } \\
\text { 4. Wiki: encontrar títulos para os parágrafos } \\
\text { destacados } \\
\text { TEXTO 3: "HERKUNFT EINIGER } \\
\text { LEITBEGRIFFE" } \\
\text { 5. Wiki: reunir conceitos centrais da filosofia } \\
\text { Kantiana } \\
\text { 6. Leitura de excerto e posterior discussão em } \\
\text { fórum dos conceitos apresentados no texto (Fórum: } \\
\text { Entendendo conceitos) } \\
\text { TEXTO 4. KRITIK DER REINEN VERNUNFT } \\
\text { 7. Link: Apresentação do texto com destaque para um } \\
\text { excerto } \\
\text { 8. Fórum: Discussão em fórum sobre: a) os } \\
\text { substantivos presentes, b) a tradução mais adequada } \\
\text { para o excerto indicado }\end{array}$ \\
\hline
\end{tabular}




\begin{tabular}{|c|c|c|c|}
\hline & $\begin{array}{l}\text { TEMA DO } \\
\text { MÓDULO }\end{array}$ & OBJETIVOS & $\begin{array}{l}\text { NÚMERO DE ATIVIDADES NO } \\
\text { MÓDULO/TIPO DE FERRAMENTA } \\
\text { UTILIZADA/TEMA OU OBJETIVO }\end{array}$ \\
\hline 6 & $\begin{array}{l}\text { Friedrich W. } \\
\text { Nietzsche } \\
(1844-1900)\end{array}$ & $\begin{array}{l}\text { Ler, compreender } \\
\text { e discutir ideias } \\
\text { centrais e textos de/ } \\
\text { sobre os estudos de } \\
\text { Nietzsche (literatura } \\
\text { secundária e texto } \\
\text { original) }\end{array}$ & $\begin{array}{l}\text { TEXTO 1: INHALTSVERZEICHNIS VOM BUCH: } \\
\text { "FRIEDRICH NIETZSCHE-PROFILE" } \\
\text { 1. Link: índice do referido livro } \\
\text { 2. Wiki: construção colaborativa de textos em } \\
\text { Português sobre cada um dos capítulos } \\
\text { TEXTO 2: "NIETZSCHES GRUNDLINIEN: } \\
\text { DIAGNOSEN UND PERSPEKTIVEN" } \\
\text { 2. Suposiçóes sobre o conteúdo do texto previamente } \\
\text { à leitura (em wiki) } \\
\text { 3. Atividade individual de compreensão do texto } \\
\text { TEXTO 3: "LEHRSÄTZE ÜBER NIETZSCHES } \\
\text { PHILOSOPHIE“ E "JENSEITS VON GUT UND } \\
\text { BÖSE" } \\
\text { 4. Fórum de discussão sobre os postulados do } \\
\text { pensador } \\
\text { 5. Fórum: Tradução do primeiro parágrafo do } \\
\text { texto “Jenseits....” de Nietzsche. }\end{array}$ \\
\hline 7 & $\begin{array}{l}\text { Karl Marx } \\
(1818-1883)\end{array}$ & $\begin{array}{l}\text { Ler, compreender } \\
\text { e discutir ideias } \\
\text { centrais e textos de/ } \\
\text { sobre os estudos } \\
\text { de Marx(literatura } \\
\text { secundária e texto } \\
\text { original) }\end{array}$ & $\begin{array}{l}\text { TEXTO 1: "MARX' AUSGANGSPUNKT" } \\
\text { 1. Atividade individual: Questóes de compreensão do } \\
\text { texto e de reconhecimento de estruturas sintáticas } \\
\text { TEXTO 2: "SOZIOLOGIE DER ERKENNTNIS } \\
\text { UND IDEOLOGIE" } \\
\text { 2. Atividade individual: questóes de compreensão do } \\
\text { texto e de reconhecimento de estruturas sintáticas } \\
\text { 3. Fórum: Discussão das respostas da atividade } \\
\text { anterior } \\
\text { TEXTO 3: "ZUR KRITIK DER POLITISCHEN } \\
\text { ÖKONOMIE" } \\
\text { 4. Fórum: discussão do texto: sobre a tradução e as } \\
\text { estruturas sintáticas e os sentidos }\end{array}$ \\
\hline
\end{tabular}

Fonte: Elaboração própria.

Os dados da análise apresentada neste trabalho foram gerados nas discussões realizadas em quatro atividades: 1) Módulo 3: Atividade 3 (Fórum: O que é tradução?) ${ }^{9}$, que tinha como tema a discussão sobre o processo tradutório e 2) Módulo 5: Atividade 6 (discussão sobre termos filosóficos) e Atividade 8b (tradução de excertos) e 3) Módulo 6: Atividade 5, na qual excertos de textos filosóficos em alemão deveriam ser traduzidos colaborativamente, ou seja, a partir da tradução conjunta dos participantes.

9 Ver Tabela 1. 
A partir da triangulação dos dados obtidos e da articulação desses com a teoria, buscaremos elucidar o que consideramos representar a noção do processo tradutório dos participantes.

\section{A concepção de tradução entre alguns estudiosos da filosofia: discussão dos dados}

Objeto de análise do presente artigo, o curso Deutschlesekurs: deutsche Philosophen proporcionou aos estudantes de filosofia e demais interessados pelo tema algumas oportunidades para discussóes via fórum sobre questóes relacionados à traduçáo e ao ato tradutório. Como citado anteriormente, a leitura pode ser considerada uma tradução, e os alunos, já familiarizados com leituras de textos originais na língua alemã, estão sempre expostos ao trabalho de compreensão de textos e escolhas tradutórias em sua vida acadêmica.

É importante mencionar que os participantes, mesmo não sendo diretamente ligados aos estudos da traduçáo, demonstraram conhecimento ao refletir sobre o tema, o que pode sugerir que já interiorizaram alguns conceitos relacionados ao trabalho do tradutor, a partir das experiências que tiveram com suas leituras e estudos e, também, a partir do senso comum de qualquer acadêmico que trabalha com noçóes de formaçáo do sujeito. Talvez tenha contribuído para isso, ainda, o fato de que, assim como a tradução, a filosofia é uma área de estudos ampla que dialoga com vários outros campos do conhecimento. Para ilustrar tal afirmação, seguem definiçôes dadas por participantes para a tradução ${ }^{10}$ :

Traduzir é realmente uma tarefa muito delicada considerando os aspectos sobre os quais já debatemos que influenciam diretamente na interpretaçáo, sendo eles: contexto cultural, contexto linguístico, conhecimentos prévios sobre o assunto, interpretaçáo pessoal, etc... - DGA (grifo nosso).

[...] muitas vezes ouvimos alguém dizer que uma tradução é 'ruim', mas como nenhum leitor é imparcial, na minha opinião a interpretação deste leitor em particular tem grande influência sobre isso. Afinal, uma outra pessoa pode achar essa mesma tradução boa. Bom, isso fica claro quando há várias traduções da mesma obra, e alguns preferem umas, outros preferem outras - DBS (grifo nosso).

\footnotetext{
10 Todas as falas aqui citadas aparecem da forma como foram postadas nos fóruns do curso, sem revisão ortográfica, estilística ou reestruturação do texto. As alternativas usadas para ênfase (sublinhar, inserir negrito ou itálico e usar letras maiúsculas) pelos cursistas também foram mantidas. Para preservaçáo da identidade dos participantes, foram criadas iniciais fictícias para cada cursista que figura como sujeito deste trabalho.
} 
[...] acredito que toda tradução, assim como toda leitura, tem necessariamente um componente interpretativo, pois toda compreensáo está mediada pelas vivências, interesses e pelo contexto histórico-político e social no qual o leitor/tradutor está imerso - JPS (grifo nosso).

Nota-se que as discussóes trouxeram ricas reflexóes sobre o que é traduzir, qual é o papel do tradutor e sobre a forma como alguns termos podem ser traduzidos da língua alemã para o português, de acordo com as escolhas tradutórias de cada tradutor. Nas descrições sobre o ato tradutório e a tradução, observa-se que são citadas noções diferentes e até conflitantes sobre tradução, as quais dialogam diretamente com as correntes de estudiosos citadas no referencial teórico do presente artigo.

Alguns cursistas citaram, ainda, diferenças entre tradução e versão. Segue, para ilustrar essa questão, a fala de um dos participantes:

Versar é transcrever um texto de uma língua para outra trazendo o significado das palavras de forma coerente e com coesão, mostrando uma versão do texto, cabendo aqui uma interpretação do contexto, quase um parafrasear. Agora, TRADUÇÃO é a compreensão do conteúdo em outra língua transformado em COMPREENSĀO para a nossa língua com a identificação SEMÂNTICA dos termos. Aqui, é preciso conhecer as palavras da língua original com o seu significado a fim de SUBSTITUIR este termo por um termo correspondente em nossa língua, que traga o mesmo significado ou um significado próximo da língua estrangeira - MTG.

MTG constrói uma lógica plausível, dentro de um determinado contexto, para justificar essa diferenciação que acredita existir, mas vale ressaltar que versão e tradução podem também ter o mesmo sentido, em uma concepção ampla do termo. Dois dos participantes chamam a atenção para essa mesma questão, colocando uma visão diferente da do colega:

A meu ver a diferenciação entre fazer uma 'versão' ou uma 'tradução' seria mais válida no campo da música ou para a tradução de títulos de filmes. Na filosofia toda tradução acaba envolvendo fazer uma versão para outra língua, tentando sempre que possível buscar a correlação mais próxima entre os termos - RFH.

[...] tudo é tradução e, como não haveria de fato um sentido último a ser tido como o verdadeiro, ou não há traição, ou tudo é traição. A diferença entre verter e traduzir seria nesse sentido apenas aparente, traduzindo nossa necessidade de classificar, diferenciar, analisar, distinguir o bem do mal - MSCM. 
Outros cursistas, porém, trouxeram a ideia da tradução como traição, própria de alguns teóricos logocentristas, curiosamente no bom ou no mau sentido, como é possível verificar nas falas abaixo:

Acredito que traduzir um texto é antes de tudo um ato de 'traiçáo', por isso estamos aqui a lutar para buscar o sentido cada vez mais original do que o autor queria revelar com o texto em si, talvez nunca chegaremos a 'ouvir' o autor em seu primeiro momento de inspiraçáo e criaçáo, mas poderemos aproximar e acredito que essa é nossa responsabilidade maior com esse curso que estamos fazendo [...]. Acredito que 'traiçáo' sáo as coisinhas a mais que o tradutor coloca e muita vezes náo existe no texto original, ou mesmo palavras que são dificieis para traduzir para outra lingua por nao ter correspondente, e portanto estamos traindo a originalidade do texto em original - FLRF (grifo nosso).

Concordo com o termo 'traiçáo' no sentido que nenhuma palavra tem equivalência em uma língua estrangeira, por mais próximos que possam ser seus sentidos. É por isso que 'traduzir' é 'trair'. Pois o sentido do termo no idioma em que foi escrito nunca poderá ser 'traduzido' de forma completamente fiel. [...] Náo vejo a 'traiçáo' como algo ruim, do tipo que deturpa a obra. Seria mais no sentido de ter de fazer escolhas o tempo todo, em busca do sentido mais parecido com aquele escolhido pelo autor original - DBS (grifo nosso).

Houve, ainda, o grupo que ressaltou a tradução como arte/criação/transcriação, diminuindo a importância da questáo da "traiçáa” para revelar o trabalho do tradutor como crucial e digno de nota. Seguem trechos interessantes das postagens dos cursistas:

Traduzir é uma arte. Se não me engano essa seria mais ou menos a concepçáo de Friedrich Schlegel, a tradução seria um ato de criaçáo táo importante quanto a criaçáo original. Para a maioria das pessoas, muitas obras só passam a existir no momento em que são traduzidas para seus idiomas nativos. E o tradutor, de certa forma, determina o futuro de uma obra, essa talvez já fosse uma ideia do Benjamin. [...]. A ideia da tradução também envolve o desejo de fazer uma obra se tornar conhecida, divulgá-la, ampliá-la a círculos maiores. É claro que a obra original acaba sofrendo um pouco com a tradução, mas sem isso talvez sequer se tornasse conhecida em outras paragens que não a de seus próprios solos pátrios! RFH (grifo nosso).

Também discordo da ideia que a traduçáo seria uma 'traiçáo'. Penso que o termo 'criação', ou talvez 'co-criação' traria uma definição mais rica para a tarefa do tradutor. A meu ver, entender a traduçáo como 'traiçáo' pressupóe que o texto seria algo fixo e unívoco e que as traduçóes seriam tentativas vacilantes de se 
aproximar e expor, da forma menos defeituosa possível, aquilo que o tradutor considera como o suposto 'sentido verdadeiro' do texto. $\mathrm{Na}$ minha opiniáo, o sentido de um texto náo é algo fixo, mas, pelo contrário, emerge em cada ato de leitura, de modo que todas as traduçóes refletem, de maneira mais ou menos explícita, a interpretaçáo do leitor/tradutor - JPS (grifo nosso).

Após a leitura do texto "A tarefa do tradutor", de Benjamin, proposta no módulo 3 do curso, os cursistas passaram a incluir comentários sobre as ideias do autor em suas postagens sobre tradução. Vejamos alguns exemplos:

Pelo texto de W. B. fica claro uma perspectiva de NÂO TRADUÇÃO de um texto, em sentido estrito, uma vez que náo se pode traduzir o que é criado pelo autor, pois não se tem o mesmo sentimento no tradutor. É como ler uma Poesia e interpretá-la procurando entender o que o Poeta quis dizer e, com isso, acabamos colocando palavras na boca do poeta que nem sabemos se era isso mesmo que ele queria expressar. [...] Se pegarmos 3 traduçóes de um mesmo original, elas NUNCA estaráo iguais, pois cada tradutor tem um sentimento ao ler o texto, e isto é passado para a traduçáo, já que cada palavra do original possui um sentido e tal palavra na língua traduzida corresponde a outra palavra, mas que pode ter sentidos diferentes - MTG (grifo nosso).

Acredito que as ideias de Benjamin sobre a tradução estariam mais próximas de uma compreensão da tradução como 'criação'. No entender de Benjamin, o tradutor não pode se restringir a buscar apenas remeter o sentido do texto original ao contexto e ao uso contemporâneos de sua própria língua, como se a traduçáo fosse uma mera 'adaptação' de algo que foi escrito num idioma e contexto A para um outro idioma e contexto B. Parece-me que, para Benjamin, esta concepção de tradução como uma simples 'adaptação' ignora o fato de que todas as línguas são entidades mutáveis, de modo que, com o passar do tempo, todos os 'adaptadores', mesmo aqueles mais modernos, acabarão por serem ultrapassados - JPS.

Por fim, é possível verificar que um dos cursistas faz um resumo do que foi discutido, versando sobre as duas vertentes dos estudos tradutórios e criando a sua própria interpretação sobre tradução:

[...] segundo o que conheço, as palavras 'tradução', ou 'traduzir' etimologicamente não dizem uma traição (como no italiano) nem uma criaçáo (como na teoria sobre tradução dos irmáos Campos). Elas vêm de TRADUCERE, que tem TRANS, que diz uma mudança, como 'travessia', 'transposiçáo', e DUCERE, que diz um 'conduzir', 'guiar'. 'Traduzir' diz enfim algo como 'transpor', ou um 'pôr além', mas um transpor guiado, que tem um fio condutor. [...] Traduzir seria algo como 
a transposição do sentido expresso por uma língua para uma outra língua. [...] E nessa transposição, enfim, sempre se corre um risco, o de se perder algo, por isso a compreensão italiana como traição, pois aquilo que se perdeu termina enfim por mudar o sentido do texto no qual o original foi escrito. Já a tradução como criação expressaria a ideia de que, para exprimir o sentido dito pela palavra ou frase original, seria preciso criar um correspondente na língua para a qual se deseja empreender a tradução. - JC.

Após tais reflexões, em um segundo momento, foram propostos fóruns nos quais traduçóes de termos filosóficos foram discutidas (Módulo 5, atividade 6: Fórum "Entendendo conceitos"). Foi possível, então, elencar escolhas tradutórias dos alunos a partir do que eles entendem por cada termo da língua alemã e pela relação que fazem com palavras da língua portuguesa. Vale retomar um trecho da introdução e mencionar que essa atividade trouxe para o curso outra tendência: a tradução coletiva e colaborativa, que ganhou espaço dentro do mundo virtual, angariando adeptos para traduções em wikis e fóruns de discussões sobre os mais variados temas.

Conseguimos notar também dois tipos de tradutores em potencial, refletindo o que se apresentou nas discussóes gerais sobre tradução: o indivíduo que vê a necessidade de "transcriar" e não se sente acuado ou se vê como traidor ao fazer suas escolhas tradutórias, e o indivíduo que, mesmo sabendo que não há tradução "pura”, busca o caminho da literalidade. Em um fórum como esse, podemos notar como cada tradutor justifica as suas escolhas e, dessa forma, explicita a sua visão sobre o ato tradutório e sobre o trabalho do autor traduzido.

Para ilustrarmos o que acaba de ser descrito, seguem alguns excertos da discussão sobre a melhor tradução para o termo "Einbildungskraft":

Possui o substantivo Einbildung mais o substantivo Kraft. Seria algo como 'força, capacidade ou faculdade de imaginação'. Einbildung vem do verbo einbilden, que é formado pelo prefixo ein + o verbo bilden. Os em Einbildungskraft é um elemento de ligação, chamado de Fugen-s, podendo em alguns casos indicar genitivo. No presente caso, parece-me que se trata de genitivo, embora eu não tenha certeza - JC.

Quando comparamos as traduçóes de Einbildungskraft = faculdade da imaginação e Erkenntnisvermögen $=$ faculdade do entendimento/ reconhecimento, podemos perceber um ponto de fundamental importância na tarefa de todos os tradutores: a dificuldade (porquê náo dizer impossibilidade?) de tentarmos traduzir uma palavra "ao pé da letra" que permaneça "legível” e ao mesmo tempo preserve as minúcias e especificidades da língua original. Em todas as traduções de textos filosóficos que eu cheguei a ler e comparar com os originais, sempre encontrei adaptaçóes e escolhas literárias dos tradutores que não tinham por objetivo corresponder literalmente àquilo que está escrito, mas sim oferecer uma ideia 
do que está sendo dito ao mesmo tempo em que mantém o texto "legível" para um leitor náo versado na língua original. Parece-me que a tarefa do tradutor é sempre uma travessia na corda bamba. Se ele escolher traduzir tudo ao pé da letra, muito provavelmente o resultado será um texto literariamente truncado e de difícil compreensão. Por outro lado, se ele optar por uma tradução mais livre, que preserve o ritmo da escrita e da leitura, terá que abrir mão de uma precisão conceitual minuciosa" - JPS.

A partir destas falas, principalmente dos trechos grifados, percebe-se que o cursista JPS, por exemplo, que demonstrou preferir a concepção de tradução como criação em citações anteriores (na discussão sobre a noção de tradução), reflete o mesmo conceito em suas escolhas tradutórias. Segundo ele, a intervenção do tradutor é necessária para que o texto possa ser compreendido na língua de chegada, por mais que, de certa forma, tenhamos que abrir mão da precisão e da transcrição minuciosa de detalhes.

Já o participante JC, que em fala anterior havia descrito a tradução a partir da etimologia da palavra, demonstra que tende a trabalhar a partir dessa correlação entre os elementos que constituem a palavra também no momento em que analisa termos do alemão e tenta traduzi-los para o português. Ele atua da mesma forma em outros fóruns, como vemos aqui, onde comenta o termo Erkenntnisvermögen:

Formado pelo substantivo Erkenntniss + o verbo vermögen, com o sentido de 'ser capaz de conhecimento', ou 'poder ter conhecimento'. Entretanto, se se tratar do substantivo Vermögen, entâo seria algo como 'capacidade ou força de conhecimento'. Talvez fique melhor, porém, como 'faculdade do conhecimento'" - JC.

Ainda no mesmo fórum, outro cursista comenta o termo a partir da leitura que faz da obra de Kant, do contexto do qual o termo foi retirado para essa discussão específica, demonstrando como outras leituras e a interpretação influenciam as escolhas tradutórias do leitor/tradutor:

De fato, a tradução mais utilizada para o termo 'Erkenntnisvermögen' é Faculdade do Entendimento, para a Filosofia de Kant. Pois este é o sentido que ele emprega o termo em sua Filosofia, apesar da tradução do puro alemão nos levar a entender como 'faculdade do reconhecimento'. Se fosse aprofundar na filosofia de Kant, é isso mesmo! Uma faculdade de reconhecimento, que promove o conhecimento por meio da 'apercepção', a consciência da percepção ao sintetizar os fenômenos dados pela faculdade sensível, formulados pela faculdade do entedimento, que reconhece...sintetiza...e conhece (claro! forçando uma interpretação)" - MTG.

Para concluir, foi possível notar um exemplo prático de todas as questóes aqui comentadas sobre as diferentes formas de se conceber o ato tradutório e o papel do 
tradutor no Módulo 5, Atividade 8b (Fórum), cujo enunciado era: "A tradução mais adequada para o excerto indicado é...”.. Para essa discussão, a professora responsável pelo curso escolheu um excerto do texto "Kritik der reinen Vernunft" de Kant e pediu que os participantes compartilhassem o que eles considerariam a melhor tradução para aqueles parágrafos. Segue o trecho a ser traduzido:

Mathematik und Physik sind die beiden theoretischen Erkenntnisse der Vernunft, welche ihre Objekte a priori bestimmen sollen, die erstere ganz rein, die zweite wenigstens zum Teil rein, dann aber auch nach Maßgabe anderer Erkenntnisquellen als der der Vernunft. Die Mathematik ist von den frühesten Zeiten her, wohin die Geschichte der menschlichen Vernunft reicht, in dem bewundernswürdigen Volke der Griechen den sicheren Weg einer Wissenschaft gegangen. Allein man darf nicht denken, daß es ihr so leicht geworden, wie der Logik, wo die Vernunft es nur mit sich selbst $z u$ tun hat, jenen königlichen Weg zu treffen, oder vielmehr sich selbst zu bahnen; vielmehr glaube ich, daß es lange mit ihr (vornehmlich noch unter den Ägyptern) beim Herumtappen geblieben ist, und diese Umänderung einer Revolution zuzuschreiben sei, die der glückliche Einfall eines einzigen Mannes in einem Versuche zustande brachte, von welchem an die Bahn, die man nehmen mußte, nicht mehr zu verfehlen war, und der sichere Gang einer Wissenschaft für alle Zeiten und in unendliche Weiten eingeschlagen und vorgezeichnet war (KANT, 1990, p.2).

A partir desse texto, os participantes postaram suas contribuições e, durante a elaboração dessa tradução colaborativa, alguns comentários carregaram as noçôes diferentes de tradução que cada sujeito vinha demonstrando. A postagem que abriu o fórum foi a seguinte:

Literalmente, em uma tradução livre eu diria: 'Matemática e Física são conhecimentos teoréticos da razão, que devem determinar seu objeto a priori, o primeiro de modo completamente puro, o segundo em parte puro, mas tendo como medida outras fontes de conhecimento além da razão. A matemática desde os tempos mais remotos, até onde chega a história da humanidade, marchou pelo caminho seguro da ciência já com o admirável povo grego. Só não se deve pensar que encontrou facilmente o caminho, assim como a Lógica, onde a razão se ocupa consigo mesma, para encontrar esse caminho real <de realeza $>$, ou mais ainda o traçar para si mesma. $\mathrm{Eu}$ creio, mais ainda, que ela permaneceu por muito tempo (principalmente entre os egípcios) no simples tatear, e esta transformação deve-se a uma revolução, realizada por uma lembraça feliz de um único homem, na tentativa pela qual náo se podia mais errar o caminho, e com isso estava traçado o caminho seguro de uma ciência para seguir em todos os tempos em distâncias infinitas'- MTG.

Logo na segunda postagem, um colega responde ao primeiro participante: 
A tradução do MTG está muito boa! Mas eu não entendi algumas coisas:

1) por que a tradução de 'in dem bewundernswürdigen Volke der Griechen' como ‘já com o admirável povo grego'. Posso estar enganado, mas me parece que o 'já coloca na frase original certa conotação que ela não tem.

2) 'Allein man darf nicht denken, daß es ihr so leicht geworden, wie der Logik, wo die Vernunft es nur mit sich selbst zu tun hat, jenen königlichen Weg zu treffen, oder vielmehr sich selbst zu bahnen;' Acho que ficaria melhor assim: 'Só não se deve pensar que ela táo facilmente - como a lógica, em que a razão se ocupa apenas consigo mesma - encontrou aquele régio caminho, ou antes o abriu para si mesma - JC.

O cursista questionado, então, replica da seguinte forma:

Oi JC, Para mim é incomodo discutir uma tradução com você, pois você é bastante fiel aos termos. Isso é ótimo. No caso, eu traduzi Kant pelo 'costume da tradução'. Como sabemos, os textos de Kant não são muito bem escritos por ele, pois Kant utiliza um 'alemão latinizado'. Mas vamos lá. Na sua questão 1: o ‘já quer dizer que o fato era algo 'já' recorrenta no Povo Grego, algo que já ocorria ali! Nada além disso. $\mathrm{Na}$ questão 2: procurei dar um sentido melhor para a frase, tentando colocar as frases em ordem. Mas confessor que isso é um vício adquirido por ler Kant a certo tempo... e tentar compreender o que, de fato, ele quer dizer com o seu alemão duro de ler. Como disse antes, prefiro a suas traduçóes às minhas, pois você é mais fiel ao texto. - MTG.

Talvez por recorrer à etimologia em suas escolhas tradutórias, o que remonta à formalidade e que pode trazer a impressão de significados fixos que se modificam apenas ligeiramente ao existirem em conjunto com outros elementos, JC deu a MTG a impressão de ser rigidamente fiel aos termos e, portanto, ao texto. É interessante notar em nuances das falas que MTG, apesar de diretamente elogiar essa característica do colega, dá a impressão de estar criticando-o indiretamente da mesma forma. Por sua vez, JC responde que:

Valeu MTG! eu tenho essa doença da 'literalidade', como já tive ocasião de te contar, se não me engano. Mas essa fidelidade também não deixa de ser interpretação. Também organizo as frases para melhor entender o sentido, e às vezes nem assim consigo entender muita coisa - JC.

Outros comentários foram feitos por esses e diferentes cursistas, e em vários momentos o conjunto da obra de Kant foi citado para justificar escolhas tradutórias. Vemos, então, que as falas dos participantes contribuem para exemplificar as questóes aqui levantadas e demonstrar como a formação de cada indivíduo afeta a 
sua interpretação, sua leitura, sua tradução dos significados sociais e acadêmicos que permeiam a sua vida.

\section{Considerações finais}

A partir da leitura do material teórico sobre tradução, das discussões em fóruns e das traduçóes coletivas dos participantes, acredita-se que os cursistas, predominantemente estudantes da área de Filosofia, puderam refletir, expressar as dificuldades e a importância do tradutor e do ato tradutório e também destacar e enfatizar a presença do ethos dos leitores/tradutores em textos de chegada.

Alguns dos participantes afirmam que há teor artístico e literário no texto traduzido, que passa a ser uma transcriação, noção já destacada por Campos (1992), e não uma mera transferência de significados imutáveis de uma língua para outra. Nessa perspectiva, traduzir é uma atividade que tem como base a essência e a produção de significados. Por isso, o tradutor, antes considerado apenas um intermediário no ato tradutório, desempenhando papel secundário e inofensivo, passa a ser visto como um segundo autor, alguém que interpreta o texto de partida e nele, mesmo que inconscientemente, imprime suas perspectivas, sua visão de mundo, seu contexto histórico e social. Para esses cursistas, uma boa tradução decorre de uma boa interpretação, de uma boa leitura.

Outros participantes, por sua vez, embora acreditem que não há como resgatar o texto-fonte, pois esse existe apenas em um momento fugaz e transitório que se extingue até mesmo para o próprio autor, ainda entendem o tradutor como traidor, que deve fazer-se invisível em uma boa tradução. Tais cursistas entendem que toda leitura/tradução é uma interpretação e que não há leitura fiel, sem marcas do leitor. No entanto, parece ainda existir um predomínio da busca pela fidelidade ao original e da eterna demanda pela "verdade".

Nota-se nas falas dos cursistas, ao justificarem suas escolhas, algumas marcas de um processo que muitas vezes se estabelece apenas nos bastidores da tradução, despercebido ao leitor padrão: ainda que invisível (e talvez por isso, segundo o que se comenta, pouco valorizado e mal remunerado) em uma leitura desavisada, a tradução é um trabalho que envolve pesquisa, investigaçáo minuciosa, dúvida, conflitos internos, desafios, interpretaçóes, leituras e mais leituras.

Concebemos o texto lido/traduzido, portanto, como uma nova obra literária que carrega muito de seu leitor/tradutor consigo, muito de sua visão sobre o autor do texto de partida, seu entendimento de literatura em geral, seu conhecimento sobre os mecanismos da língua estrangeira e da sua língua materna, sua análise dos contextos culturais, sociais e históricos.

Para concluir este trabalho vale destacar, no que concerne ao ensino/aprendizagem de línguas, que a formação escolar deve buscar a formação de sujeitos leitores críticos e autônomos a partir da prática da leitura. Isso implica, assim como na traduçáo 
literária, em renunciar ao sentido convencional, imutável, ao senso comum. $\mathrm{O}$ professor deve

[...] partir da recepçáo do aluno, de convidá-lo à aventura interpretativa com seus riscos, reforçando suas competências pela aquisição de saberes e de técnicas [...]. Nesse caso se produz um fenômeno próprio da leitura literária: a alteração da obra pelo leitor e a alteraçáo do leitor pela obra. O leitor se expóe ao ler, se desapropria de si mesmo para se confrontar com a alteridade e descobrir, in fine, a alteridade que está nele (ROUXEL, 2013, p.20-28).

Para isso, é necessário que o estudante adquira, além do conhecimento sobre os gêneros textuais e literários e sobre a estrutura do discurso em sua língua e na língua estrangeira, um saber sobre si próprio e sobre sua subjetividade como leitor que é capaz de interpretar. Portanto, acreditamos que uma visão mais fechada do ato tradutório, a tradução literal, não colabora para uma reflexão epilinguística e metalinguística mais móvel e dinâmica da linguagem, visto que não fomenta a reflexáo ao buscar a reprodução de significados, um trabalho quase mecânico. $\mathrm{Na}$ tradução literal, o dicionário pode ser considerado a ferramenta mais importante, enquanto que na tradução como transcriação, a fonte principal seria o próprio tradutor (e toda a sua bagagem de conhecimento).

Dessa forma, uma visão mais livre e criativa de tradução pode ser mais fértil no sentido de possibilitar e fomentar a comparação entre línguas (culturas), entre estruturas linguísticas, mobilizando, com isso, a consciência metalinguística. Por isso a tradução inserida no ensino/aprendizagem de línguas deve ser vista como uma ferramenta que, ao invés de prender, liberta: ela fornece a oportunidade de conhecimento e interaçáo com o outro, de reflexão crítica e produção criativa tão necessária à formação dos estudantes.

Ressalta-se também a importância de cursos na modalidade a distância para o oferecimento de um programa que vai ao encontro da demanda de alunos que desejam aprender alemão para a leitura de textos filosóficos: a partir da aproximação de distâncias possibilitada pelas Tecnologias Digitais de Informação e Comunicação foi possível promover a estudiosos oriundos de diferentes partes do Brasil um aprofundamento do conhecimento linguístico, a discussão sobre possíveis traduções de textos filosóficos e sobre premissas dos pensadores abordados, a troca de experiências, e ainda a própria noção do que seja o ato de leitura e o tradutório. Destaca-se, ainda, o potencial da modalidade para a tradução colaborativa, que vem ganhando força em diferentes situaçôes que envolvem processos tradutórios. 


\section{READING, INTERPRETATION AND TRANSCREATION: CONCEPTIONS OF TRANSLATION AMONG GERMAN PHILOSOPHY STUDENTS}

- Abstract: The interest in learning German is often triggered by the desire and need of reading German texts in their source languages, a fact that is commonly observed among Philosophy students. This paper aims at presenting an e-learning German course for Philosophy students who sought linguistic enhancement in order to better understand texts of the area in their source language and focused on different conceptions of translation. To this end, we describe the course in detail and analyze the discussions held in four online forums, seeking to identify the notions of translation imbued among the course participants. The results indicate, on one hand, the validity of e-learning courses for German students with specific demands such as understanding and translation of philosophical texts. On the other hand, the considerations here presented show different conceptions of the act of translation. Our goal is to contribute to the field of translation studies, as well as highlighting an interesting way to be followed in German as a foreign language teaching and learning.

- Keywords: German as a foreign language teaching and learning. German for Specific Purposes for Philosophy readers. Translation. E-learning German courses.

\section{REFERÊNCIAS}

ALVES-BEZERRA, W. Da tradução como criação e como crítica: ruma à caracetrização de um Quiroga brasileiro. Olhar, São Carlos, v.11, n.20, jan./jul. 2009.

ARROJO, R. (Org.). Traduçáo, desconstrução e psicanálise. Rio de Janeiro: Imago Editorial, 1993.

O signo desconstruído: implicações para a tradução, a leitura e o ensino. Campinas: Pontes, 1992.

BAYARD, P. Como falar dos livros que náo lemos? Trad. Rejane Janowitzer. Rio de Janeiro: Objetiva, 2007.

BENJAMIN, W. A tarefa-renúncia do tradutor. Tradução de Susana Kampff Lages. In:

BRANCO, L. C. (Org.). A tarefa do tradutor, de Walter Benjamin: quatro traduçóes para o português. Belo Horizonte: Fale: UFMG, 2008. p.66-81. Disponível em: <http://disciplinas. stoa.usp.br/pluginfile.php/184041/mod_resource/content/1/Benjamin $\% 2 C \% 20$ a $\% 20$ tarefa\%20do\%20tradutor.pdf>. Acesso em: 13 mai. 2015.

BENVENISTE, É. Da subjetividade na linguagem. In: Problemas de Linguística

Geral I. Campinas: Pontes, 2005. p.284-293. 
CAMPOS, H. Tradução: fantasia e fingimento. In: TÁPIA, M.; NÓBREGA, T. M. (Org.). Haroldo de Campos: transcriação. São Paulo: Perspectiva, 2013a. p.27-36.

. Tradução e reconfiguração: o tradutor como transfingidor. In: TÁPIA, M.; NÓBREGA, T. M. (Org.). Haroldo de Campos: transcriação. São Paulo: Perspectiva, 2013b. p.109-130.

de. Da tradução como criação e como crítica. In: CAMPOS, H. de. Metalinguagem e outras metas. São Paulo: Perspectiva, 1992. p.31-48.

CORACINI, M. J. R. F. Discurso sobre tradução: aspectos da configuração identitária do tradutor. In: CORACINI, M. J. R. F. A celebração do outro: arquivo, memória e identidade línguas (materna e estrangeira), plurilinguismo e tradução. Campinas: Mercado de Letras, 2009. p.165-182.

DERRIDA, J. Carta a um amigo japonês. Trad. Érica Lima. In: OTTONI, P. (Org.). Traduçáo, a prática da diferença. Campinas: Ed. da UNICAMP: FAPESP, 1998.

GRIGOLETTO, M. Constituição do sentido em teorias de leitura e a perspectiva desconstrutivista. In: ARROJO, R. (Org.). O signo desconstruído: implicaçóes para a tradução, a leitura e o ensino. Campinas: Pontes, 1992. p.93-97.

KANT, I. Kritik der reinen Vernunft. Hamburg: Feliz Miner Verlag - 2 - Auflage, 1990. Disponível em: <http://gutenberg.spiegel.de/buch/3502/3>. Acesso em: 20 mai. 2015.

MARTINS, M. S. C. Ethos, gêneros e questóes identitárias. D.E.L.T.A: Revista de Documentação de Estudos em Linguística Teórica e Aplicada, São Paulo, v.23, n.1, p.27-43, 2007.

OTTONI, P. O papel da lingüística e a relação teórica e prática no ensino da tradução. TradTerm, São Paulo, v.4, n.1, p.125-139, 1997.

PAZ, O. Traducción: literatura y literalidad. Barcelona, España: Tusquets Editores, 1990.

RODRIGUES, C. C. Tradução e diferença. São Paulo: Ed. da UNESP, 2000.

ROUXEL, A. Aspectos metodológicos do ensino de literatura. Tradução de Neide Luzia de Rezende. In: DALVI, M. A.; REZENDE, N. L.; JOVER-FALEIROS, R. (Org.). Leitura de literatura na escola. São Paulo: Parábola, 2013.

SÁ, L. F. F. Por uma tipologia da tradução ou por re-constelaçôes tipológicas. Cadernos de Traduçáo, Florianópolis, n.4, p.58-85, 1996.

SHREVE, G. M. Cognition and evolution of translation competence. In: DANKS, J. H. et al. (Org.). Cognitive Process in Translation and Interpreting. Thousand Oaks: Sage, 1997. p.120-136.

TÁPIA, M.; NÓBREGA, T. M. (Org.). Haroldo de Campos: transcriação. São Paulo: Perspectiva, 2013. 